\title{
LA POESÍA DE JUAN MALPARTIDA COMO CONSTRUCCIÓN DE SENTIDO
}

\author{
THE POETRY OF JUAN MALPARTIDA \\ AS CONSTRUCTION OF MEANING
}

\author{
Juan Carlos ABRIL \\ Universidad de Granada \\ jca@ugr.es
}

\begin{abstract}
Resumen: La obra poética de Juan Malpartida no se ajusta al canon español de las últimas décadas. La perspectiva que otorga su obra poética reunida se vincula a la modernidad de la que hablara Octavio Paz, a las corrientes europeas de vanguardia, y no al realismo, tan característico de España. Su poesía busca la construcción de sentido a través de una semiosfera - en términos lotmanianos - que indaga en la arqueología del saber, tal y como quería Foucault. Se ponen en otra dirección semántica los símbolos, en su mayoría bisémicos, y las palabras, motivadas por la influencia de otras tradiciones. De este modo se articula la interdisciplinariedad de otras artes, su transversalidad, la lectura mitocrítica de la cotidianidad, la relación gestáltica entre teoría y práctica, la función cognitiva de la escritura, o la reflexión metapoética.
\end{abstract}

Palabras clave: Juan Malpartida. Análisis discursivo. Transversalidad. Trayectoria. Piedra. Sentido.

Abstract: The perspective of the poetic work of an author such as Juan Malpartida does not conform to the Spanish canon of the last decades. The vision and perspective of his poetic work is linked to the modernity Octavio Paz would speak about, to the European avant-gard currents, and never to the realism, more characteristic of Spain. His poetry seeks the construction of meaning through a semiosphere, in terms of Lotman. This construction investigates the archeaology of knowledge, as in Foucault. 
The mostly bisemic symbols are placed in another semantic direction, and so do the words, motivated by the influence of other traditions. Thus, the interdisciplinarity of other arts, their transversality, the mythocriticism reading of everyday life, the gestural relation between theory and practice, the cognitive function of writing, or the metapoetic reflection are all constructed.

Key Words: Juan Malpartida. Discursive analysis. Transversality. Trajectory. Stone. Meaning.

\section{DIALÉCTICA, ESPIRAL, MATRICES SEMIÓTICAS}

La poesía de Juan Malpartida (Marbella, Málaga, 1956) es una invitación a la arqueología de la memoria, entendida esta como algo vivo, presente. Lo remoto y su paso resuelto en lo que permanece, así sea como un pecio o fragmento, siempre a la búsqueda de un sentido foucaultiano de las ciencias humanas y el saber, para averiguar nuestro origen o punto de partida. Puede observarse no solo en su obra poética sino también en su narrativa, en diversos ensayos y sus diarios. Por lo demás, la obra poética de Malpartida abarca de manera explícita y en su transversalidad la ciudad moderna, la observación atenta del mundo natural, el erotismo y el amor... Sea como fuere, la poesía es en sí misma un punto de origen y no solo de llegada. Lo que vemos y oímos nos permite percibir de otra manera. Un rastreo hacia no se sabe dónde. Una reminiscencia, en efecto, flota en sus poemas, retrotrayéndose a la conciencia anterior de nuestra noción de historia, arraigando en el mito, en la primera matriz dialéctica fértil, mythos/logos, con la consiguiente lectura mitocrítica que enriquece cualquier aspecto - axial para nuestro análisis- epistemológico. Aunque ha habido acercamientos críticos a su obra poética, ahora con cierta perspectiva queremos subrayar la importancia de esta poesía en el panorama hispánico, y su singularidad en el contexto español.

Hay que arrancar cualquier lectura desde la transversalidad temática y estética, ética y antropológica subyacente, que inicia en Espiral (1990) —su primer poemario, aunque hubiera publicado poemas en revistas desde mediados de los ochenta- y se cierra por el momento en $A$ un mar futuro (2012). Una herramienta compositiva recurrente en su obra 
enlazará formal y temáticamente los poemas unos con otros, las partes o secciones, los libros, repitiendo a modo de emblemas ciertos asuntos que, más que obsesivos, que también, son motivos por los que circula su poesía, versos que surcan la página, canales por los que discurre lo que, en boca del propio poeta, sea posiblemente el mismo poema: "Publicado en 2012, A un mar futuro es el libro más reciente de Juan Malpartida, pero también puede decirse que es la consecuencia o el resultado - la evolución, para decirlo más exactamente- de impulsos, preocupaciones y motivos que arrancan desde su primer libro" (Sánchez Robayna, 2015: 41). Se afirma en "Los días del tiempo", epílogo a Huellas (Poesía 1990-2012):

[...] como el que escribe el mismo poema, una suerte de palimpsesto donde más que borrar y escribir encima, sobre un mismo soporte, hay una superposición: ecos, traducciones, traslaciones, alteraciones. Tengo la impresión, a pesar de las obvias diferencias de muchos de ellos, en sus formas y contenidos, que he estado escribiendo siempre el mismo poema (Malpartida, 2015: 332)1.

Se suele atribuir a varios autores la conocida frase "siempre se escribe el mismo poema", pero no existe datación fija sobre quién la usó, ni cuándo, y más bien se trataría del recurso intratextual al modo de Genette. Este leitmotiv no deja dudas sobre lo que abarca, a propósito de esos materiales - entendamos semióticos - de un autor que giran alrededor de sí mismos y que, a pesar de innegables evoluciones, nunca cambian realmente. Lo constata Fabio Morábito: "Hora rasante no representa una ampliación del universo poético de su autor, de una coherencia y singularidad raras entre nosotros, sino más bien una afinación de los elementos que articulaban entregas anteriores" (1998: 47). Son más bien introspecciones, sondeos que se extienden a cuestiones estilísticas y formales. Id est: existe para bien y para mal una óptica, una manera de entender que todos poseemos, una perspectiva, una experiencia y una imaginación, etc., por la que estamos determinados por los mismos temas, si bien la semiosfera - en términos lotmanianos - que nos circunscribe podría considerarse un universo en expansión "pleno de refracciones y atmósferas" (Martínez Ruiz, 1990: iv), como en el caso de la poesía que

${ }^{1}$ Siempre que sean citas de Juan Malpartida, dejaremos solo la referencia con la fecha y las páginas. 
nos ocupa, una espiral que se mueve hacia fuera, de manera centrífuga, y que por tanto ofrece interpretaciones en continuo desarrollo. "Concibe Malpartida, de este modo, la función del arte como generador de una fuerza que continuamente deshace, cuestionándolo, lo creado" (Ferrer Solá, 1990: XX). Se trata de un universo en expansión. Así lo define Octavio Paz en 1989, publicado un año después:

Espiral es un libro de poemas, mejor dicho, un poema que se dispersa en muchos poemas pero solo para volver, una y otra vez, al punto de partida. Un punto que, sin cesar de ser el del comienzo, es siempre distinto. Variaciones y recurrencias, repeticiones y transfiguraciones, vuelo y gravitación, diálogo constante entre lo otro y lo mismo. Espiral, torbellinos y remolinos, formas aéreas y acuáticas al fin resueltas en una caracola resonante. Un poema.

En el libro de Juan Malpartida giran y se entrelazan voces y ecos, formas y reflejos: el cuerpo que piensa, el pensamiento que encarna (Paz, 1990: s. p.).

La imagen de la espiral es un resumen abstracto de diferentes figuras que se encuentran en la naturaleza. El propio Malpartida, en el epílogo citado, se hace eco de esta imagen que fue el título de su primer libro. A Espiral (1990) sucede Gravitación (1990), Bajo un mismo sol (1991), Canto rodado (1996), Hora rasante (1997), El pozo (2002) y, tras una década de silencio, A un mar futuro (2012). El poeta confiesa, mucho después de sus dos primeras entregas, aparecidas en un solo volumen en la editorial Anthropos, "que me habría gustado titular el conjunto de mi obra poética Espiral y gravitación" (2015: 331). Después realiza un alegato y recuerda lo que significan y simbolizan las espirales, las hélices, y lo que supone sentir la fuerza que la gravedad ejerce sobre la espiral que "impide que se pierda, del juego a la fantasía, como un globo en el cielo" (2015: 332). Sin embargo, se inclina por el uso de la palabra "huellas" para el título del conjunto ${ }^{2}$, pues posee una resonancia menos abstracta y más histórica, más antropológica y arqueológica, aludiendo a la poesía

${ }^{2}$ La poesía, sin embargo, no es un acta notarial de la realidad, y "Escribir no está destinado a dejar huellas, sino a borrar, con esas huellas, todas las huellas, a desaparecer en el espacio fragmentario" (Blanchot, 1994: 81). Se trata de huellas que borran todas las huellas a través de la poesía. 
como una "impresión en el tiempo" (2015: 332). Y en la página siguiente apostilla: "Un poema, tomado en su última significación, en la más humana, es solo una huella, el testimonio, sea grande o pequeño, perdurable o fugaz, de la vida" (2015: 333). No puede ser más meridiana la definición, y útil para nuestro análisis. Continúa el poeta haciendo un breve y personal recorrido por esas huellas que, desde el Gilgamesh hasta hoy, han incidido en nuestra historia, literaria o no, estableciendo paralelismos en ocasiones, por poner un ejemplo, entre los trilobites del Cámbrico y las huellas más antiguas de la historia humana encontradas en Tanzania, o las pinturas rupestres de Lascaux: "En muchas cuevas de ese periodo se encuentran huellas de manos con pintura en las paredes" (2015: 334). A propósito, huellas de manos - las de la cueva de Salta, en Argentina - ilustran la cubierta del libro, y desde esta perspectiva paratextual añadiríamos otro elemento para la exégesis, pues se trata de una vuelta al inicio en la que la mirada investigadora del poeta-arqueólogo (aventurero, al fin y al cabo) se configura fundamental para comprender el contenido de la historia del hombre, el camino recorrido a través de las huellas marcadas en el arte. Conviene subrayar que en la dialéctica realismo/abstracción se hallan las técnicas más importantes — al menos decisivas — de la historia de los movimientos artísticos, y desde sus orígenes se ha alternado figuración y abstracción, como bien argumentara el volumen clásico de Nougier, El arte prehistórico.

\section{REPLIEGUE GESTÁLTICO. HACIA EL SENTIDO}

La imagen de la espiral es un resumen abstracto de diferentes figuras que se encuentran en la naturaleza. La arquitectura y el urbanismo, como cualquier arte funcional, también se inspira en la naturaleza. Y más al retrotraernos a los orígenes de la humanidad. El poeta construye su mundo basado no solo en la experiencia, que puede ser relativa, sino sobre todo poemática: "La poesía no solo era experiencia de una situación sino experiencia del poema, y esto es algo que, sin desdeñarla, nos lleva más allá de la anécdota." (2015: 330). Una correlación de la existencia, en este sentido, podría averiguarse desde cierta perspectiva Gestalt en la que las "siluetas" — traducción directa del alemán- de lo que al fin y al cabo son las ideas, se corresponden con el mundo material, en el sentido constructivo del término. Nos dirá en el largo poema "Marina", de El pozo, 
que

el tiempo que yo soy lo hacemos todos, pero solo en un alma tiene cuerpo,

y algo más que palpita en las entrañas:

la fijeza del ser frente a la espuma

contemplada de pronto en mi memoria;

no el recuerdo: reminiscente imagen (2015: 232).

Se observa asi que este poema, "Marina” (señalado por Díaz de Castro como "el mejor del libro", 2002: 27, de El pozo), luego desembocará en A un mar futuro, en la búsqueda de la identidad. "[A]lguien, en fin, que pregunta por su identidad. Es esta una poesía, pues, concebida como vía de conocimiento y autoanálisis" (Prieto de Paula, 2002: 18):

Somos lo que no somos, un reverso,
manojo de preguntas y respuestas
creciendo en espiral sobre la nada,
un reverso que busca el otro lado,
metáfora de sí, puente que cruza
las invisibles aguas de este río
hecho de negaciones (2015: 232-33).

Gestalt que coincide con nuestra teoría, visión y explicación, a partir de la lingüística cognitiva. Pensar las cosas es crearlas. La tradición filosófica general —y la corriente analítica en particular — ha insistido en el nulo valor cognitivo de la metáfora ("ni imagen somos ni naturaleza", dirá nuestro poeta en "Una vez más, la realidad", 2015: 147), recordando Metáforas de la vida cotidiana, de Lakoff y Johnson. Frente al tradicional desprecio filosófico hacia la metáfora, sugerimos su carácter ubicuo, "pervasivo", dicho con otras palabras, puesto que la metáfora se halla por todos lados, y tiende a difundirse. "Metáfora, me despierto / en medio del universo" (en "Metáfora", de Hora rasante, 2015: 145), escribirá el poeta:

"Metáfora" postula una concepción del poema como un tablero de ajedrez donde tesis y antitesis disponen sus peones visuales: la metáfora es un "gallo de siete colores", un "big bang" que altera el 
orden del universo, pero ese universo es también el vecindario que el escritor observa desde su balcón, y lo que observa cambia con el pensamiento, que es tanto metáfora como memoria ("recordando no sé qué"). En este movimiento circular del poema, en esta espiral que las palabras encarnan sobre la página, todo es todo, todo juega a ser todo: el mundo es parte realidad sentida y construcción del lenguaje, parte realidad soñada y recuerdo; el yo, incuestionable en tanta poesía actual, es aquí una construcción tentativa, una duda o interrogante que palpa constantemente sus límites y grietas y que sabe que solo las palabras, a su vez irreales, sustentan su realidad (Doce, 2007: 16).

Así, Eduardo Milán asegura que "Malpartida ve el mundo como metaforizado. No ya la metáfora incrustada naturalmente en la lengua: la metáfora incrustada en el mundo.” (1990: 30). Hablamos de metáforas en estricto sentido lingüístico, y no de ocurrencias o iluminaciones poéticas. Aludimos a la más íntima estructuración del lenguaje, pero también de la naturaleza y del arte que imita a la naturaleza, etc. Esto podría llevarnos a afirmar la metáfora por encima o por debajo de los significados literales, con lo que se realza la lectura abstracta e individual de la otredad:

La lectura y la escritura de poemas me hacían conocer a otro, que era yo mismo pero solo en la medida en que, cada vez que se manifestaba como yo, me llevaba fuera de mí. Lo diré de otra forma: gracias a la poesía, a la que leía o escribía, mi yo era cada vez más y más el momento de sostén de una vastedad que siempre significaba mundo. En Octavio Paz aprendí a pensar esa hermosa relación de la poesía como otredad (2015: 331).

Dialéctica poesía/mundo como resultado de esta visión gestáltica. Nos adentramos en la primacía de la metáfora sobre la literalidad, que se encuentra también en Gadamer o Ricoeur (este hablaba de las “metáforas de creación”). Pero las metáforas no están en las palabras sino en los conceptos mismos; por tanto, hay que analizar la estructura de estas metáforas para llegar a los conceptos. Fabio Morábito hablaba de "la profunda naturaleza sinestésica de la poesía de Juan Malpartida" (Morábito, 1998: 47), señalada también —“su ley es la metamorfosis”- 
por Jordi Doce (1997: 19-21). Matizada después al añadir: "Esta poesía, de gran carga reflexiva, se distingue así de propuestas afines por el acento que pone en la metáfora y el brillo verbal." (Doce, 2002: 14). Abstracción y concreción, borrar la parte concreta de una identidad para suplantarla por otra, dejando al descubierto la forma abstracta de la primera. ¿Y por qué se realiza este procedimiento? Sin duda para definir mejor la propia identidad, que no se puede singularizar sino en función de sus relaciones semánticas/desemánticas. La diferancia, que diría Derrida. Identidad (ver el poema homónimo "Identidad", de El pozo, 2015: 188-89) de poeta que vive - habita - el lenguaje como ser en el tiempo, que esculpe ("escribe como en una piedra”, Ríos Ruiz 1990: 14) o edifica con su lenguaje, y pasión en medio de lo cotidiano:

La dicción poética, impresión digital del poeta en la arcilla del lector, reconocible en la alfarería del poema, es correlativa a la vivencia subjetiva (pre-verbal y anterior a aquella) del flujo poético que el poeta intuye, siente y ve emanar de su experiencia con lo "real" - que incluye, lógicamente, su relación con la literatura-, en el magma que envuelve su relación con el mundo, en la lava silenciosa e incesante del estar (Costa, 1991: 5).

Como en las "meditaciones de un día" machadianas de "El otoño en esta calle (Novela)": "Pasión no es geometría, / pero sin la forma la pasión / no tiene rostro" (de Gravitación, 2015: 51). Y se refrendará en el poema siguiente, "Comienzo del día", porque "Pasión es gravitar al centro" (2015: 53). Reflexión identitaria que también plantea la duda metapoética como preocupación:

Vuelvo a mi mesa, teatro sin presencia,

y observo la resina de lo escrito,

la opacidad, espejo de mi imagen,

palabras

trabadas más allá de lo visible

y que dentro de mí, bajo la sombra,

aguardan la transparencia (en "Sombra y viento", de El pozo, 2015: 202). 
Las palabras son "relámpagos sobre la mesa" (en el poema homónimo "El pozo", 2015: 183). Sin escatimar la anécdota, no obstante "la gran diferencia reside en la actitud de Malpartida ante la cuestión de la alteridad" (Guerrero, 2002b: 20), que abordaremos a continuación. Y en ese sentido, a propósito de Hora rasante:

El título es un poco enigmático pero deja entrever el motivo central de casi todos los poemas: la hora, el tiempo, en ciertos momentos, desnuda a las cosas y a las personas de su apariencia y las deja en su esencialidad. Una esencialidad que con frecuencia llamas vacuidad. ¿Budismo? No lo creo. Más bien reconocimiento de que las cosas (y las personas) son inasibles: no se reducen ni a sus apariencias ni tampoco a su significado. Son, simple y misteriosamente son. No se puede decir más de ellas ni de la vida... Sea exacta o no mi interpretación, encuentro en tu pequeño un tono que no percibo en casi toda la poesía de los jóvenes. Un tono a un tiempo grave y simple. Misterios diáfanos podrían llamarse esos instantes. Tu libro tiene, en ese sentido, mucho de un diario: los poemas como anotaciones de instantes en los que no pasa nada, salvo el tiempo que abre una ventana hacia una realidad propiamente indecible. La factura de los poemas es simple, clara y, tras esa claridad, el lector atento percibe la compleja y misteriosa aparición del tiempo. Hora rasante: hora de la caída de las apariencias... Tu pequeño libro continúa tus poemas inmediatamente anteriores pero no es una repetición sino una pausa. Digo esto porque, al final, en los tres últimos poemas, especialmente en "Para no olvidar" y "Caracola", entreveo el comienzo de una exploración poética distinta. La realidad no se disuelve en la contemplación sino que se afirma en su singularidad única. Presiento nuevos horizontes para tu poesía (Paz, 2011: 258-59).

Al hilo de lo que apunta el Nobel mexicano, las palabras establecen una relación sensible con la realidad, desde el que las escucha en la poesía, "en el fondo sin fondo del tiempo" (en "Fábula y un poco de viento", de Canto rodado, 2015: 115), hasta "el fondo sin fondo de las horas" (en "Caracola", de Hora rasante, 2015: 176). Podríamos hablar, con salvedades, de una suerte de poesía en movimiento. Porque "busca[n] una 
certeza que no pese / en el espacio incierto del nosotros" (en "El fantasma y sus apariciones”, de Bajo un mismo sol, 2015: 68). O también:

Escribir, apurar el tiempo de esta copa, sostener la inclinación irregular del cuerpo sobre un fragmento del mundo, es una forma de oír ese reverso, lo que es y pudo no haber sido, lo que está del otro lado haciendo con su ausencia el lado en que vivimos (en "La casa", de Bajo un mismo sol, 2015: 74).

En el deíctico "Aquí (allá)" (2015: 90-91), comienza: "Desde hace horas / veo algo que hace señales / tras la ventana.". Y acaba: "Desde hace horas / veo algo que me hace señales / desde esta página.", estableciendo una relación sígnica y metaliteraria inexorable entre lo de afuera y lo de adentro. Una vez más la concepción centrífuga de la espiral. En "Estas palabras" (2015: 105-06), primer poema de Canto rodado, se define la poesía como "[...] palabra más alta que el lenguaje, / pero es, como nosotros, inexacta", 2015: 106). Como lectura, en su oralidad o escritura, en su textualidad, las palabras se encumbran como punto de unión, espacio intersticial que nos une. Palabras o huellas como figuras o siluetas, aunque literalmente se muestren en forma de palimpsesto. Ya lo hemos apuntado.

El signo que él [Juan Malpartida] imprime en las cosas al nombrarlas es a la vez un molde que refleja su propia imagen. La poesía no consiste en otra cosa que en abrir huecos de silencio en lo real con la palabra en busca de eso que llamamos realidad, la conciencia de ser. En ese afanarse hacia la luz termina por comprender que la poesía nace en la rasante del decir y el callar, de la visión y la ceguera (García de la Concha, 1997: 9).

Pero si la mayor parte de nuestro sistema conceptual — normalse estructura metafóricamente, esto es, si la mayor parte de los conceptos se entienden al menos parcialmente en términos de otros conceptos, la cuestión que surge de inmediato es la de cuáles son las bases de ese sistema conceptual. Juan Malpartida lo sintetiza con su personal cronotopo, tras la 
constatación de que espiral/gravitación son el diálogo o la imagen de su obra poética, aclarando que

[s] in embargo, ahora, al recoger mi poesía, dejando atrás algunos poemas, he preferido agavillarlos bajo el término huellas. Si la espiral y la gravitación hablan de geometría y física, la huella es algo más simple y frágil: la impresión en el tiempo [...] Huella: "Señal que deja el pie del hombre o del animal en la tierra por donde pasa". La definición sería exacta, incluida la mención del animal, si en vez de pie se ampliara a cualquier parte del cuerpo, o de la actividad de la mente. Hombre o animal [...] eminentemente lector. Un lector que escribe, que deja signos. Sus huellas son signos, metáforas, palabras escritas. Un poema, tomado en su última significación, en la más humana, es solo una huella, el testimonio, sea grande o pequeño, perdurable of fugaz, de la vida (2015: 332-33).

Nos hallamos ante una teoría constructivista del lenguaje y del pensamiento, pero se trata de una construcción a partir de la experiencia común y cotidiana, invitando a una relectura de la intimidad que aporta una visión oblicua nada convencional, y que nos llevaría muy lejos en nuestras reflexiones: un sesgo no transitado en nuestra más reciente tradición española (ver, por ejemplo, "Visión I" y "Visión II", de Bajo el mismo sol, 2015: 92-93). Porque "[s]in intimidad no hay universo" (nos diría un poco antes, en "La resta", 2015: 89). La poesía de Juan Malpartida ofrece otra lectura de la intimidad, algo muy ajeno a la tradición literaria practicada en España en las últimas décadas, y cabe destacar su importancia no solo en la trayectoria de nuestro autor, sino para resituar el contexto de su generación poética a un lado y otro del Atlántico (ver Ulacia, 1990: 12-13), ya que se encuadra en el marco de la lengua española. Por su filiación, se expande en una modernidad que no ha sido muy visitada en España o, cuando lo ha sido, no ha arrojado por lo general muestras de talla considerable y valor lírico, como la que aquí nos ocupa. Ahora podemos leer y releer la obra poética de Juan Malpartida a la luz de nuevas coordenadas, lejos de las categorías dialécticas duales y disecciones maniqueas en las que se instaló nuestra poesía más reciente. 


\section{HUELLAS PARA UNA POÉTICA ARQUEOLÓGICA}

Los subelementos de la estructura obtienen su significado de una Gestalt compleja que organiza nuestra experiencia, entendiéndola como una estructura que abarca lo abstracto y lo concreto, lo grande y lo pequeño, lo de arriba y lo de abajo, etc., y que luego es capaz de ser deglutida, en la comunicación normal, como discurso - en este caso, poético - conjuntando idealismo y materialismo. De ser encadenado, comprehendido como discurso ("una voluntad real de luchar contra la opacidad e las cosas, de apoderarse de los límites, y a través de ello rehacer el discurso", Cobo, 1990: 7). Desde este proceso gestáltico afrontamos las complejas realidades de los valores que nos envuelven e históricamente se ven denigrados, tales como el diálogo o la tolerancia, la dignidad, la condición humana, la voluntad, etc., tan decisivos en la obra poética de Malpartida. En su propuesta formal se alterna la dialéctica verso/prosa, plasmándose en excelentes poemas en prosa desde sus inicios (para Gustavo Guerrero, "Esta noche" (2015: 28-30) será lo mejor de Espiral) hasta A un mar futuro. El mundo de la vida se estructura metafóricamente. La lingüística cognitiva, aparte de afrontar estas problemáticas, rompe con la creencia esencialista de los universales (sean religiosos o no) como entidades lejanas, etéreas y eternas (más o menos platónicas), alejadas de la realidad, para acercarlas al propio proceso lingüístico de creación de sentido. Y los valores tienen un sentido, aunque el poeta se encuentre al principio de Espiral, desde su primer poema, desasosegado con la certeza de que lo que escribe es una sorda lucha — el agón — que no lleva a ningún sitio, impelido por el ser-para-la-muerte heideggeriano. Por eso intenta su particular "Reconstrucción del tiempo" (2015: 15-16) como lema de indagación en el propio deseo, en su perdurabilidad a través de lo que fuimos y, si acaso, de lo que aún nos queda por vivir.

La escritura en la obra de Malpartida se propone fijar el tiempo, obsesión que aparece y reaparece como uno de los temas importantes. De ahi que en toda la obra exista también la correspondencia vida-escritura. El lenguaje, por tanto, es un cuerpo deseante y deseado, una máscara más de la fuerza inefable que genera lo creado. Si Malpartida es consciente de que la escritura es una forma de fijar el tiempo, también tiene consciencia de que este gesto es una 
imposibilidad. La escritura es la creación de otro tiempo (Ulacia, 1990: 12-13).

A la interpelación inicial: "Dime, / sombra, noche, / en qué lugar de la luz, / en qué olvidada promesa / aguardas.” (2015: 15), le sigue la poesía como única respuesta, es decir, la huella, su — nuestra - huella. O, dicho de otro modo: "palabras, mitad cuerpo, mitad nada" (de "Un poeta", en $E l$ pozo, 2015: 206).

$\mathrm{Si}$ analizamos esa huella, hurgando en lo profundo de la construcción del sentido, observaremos una concepción fragmentaria de la poesía y el mundo. Para Malpartida el fragmento se da como entero (ver 2015: 326), lo cual explica, a pesar de la capacidad de absoluto que posee, su irregularidad y singularidad. Dos teorías contemporáneas lo explican. La primera: el fragmento en su relación con el todo hegeliano, una totalidad expresiva, es decir, un lugar, un conjunto donde cada parte es solo la expresión del proceso global, de herencia luckasiana, idealista, donde cada parte representa, expresa, contiene al todo. La segunda: aquí la versión althusseriana difiere (pues ya sabemos que las líneas de pensamiento del maestro francés son distintas), y tiene que ver con la parte que posee autonomía, sus propias articulaciones, temporalidad, y no está sujeta al proceso global. Ambas nociones son muy útiles para entender la poesía contemporánea, enmarcarla en algunos procedimientos $\mathrm{y}$, sobre todo, ciertos rasgos textuales presentes en la obra de Malpartida. Walter Benjamin nos acompaña a través de sus pasajes y su murmullo de la historia. Nuestro autor asegura que:

[a] unque he amado y amo algunos poemas con voluntad de absoluto en sí mismos, geometrías casi perfectas, siempre he preferido la poesía que es capaz de mostrar irregularidad, el desplazamiento de la sombra. En alguna medida, y no menor, el mundo de la poesía es fractal. Las formas fractales existen en la naturaleza y se caracterizan por no ser triángulos, rectángulos, cuadrados, es decir: los fractales son formas a las que no se les puede aplicar la geometría euclidiana, sin duda perteneciente a un mundo más abstracto. Son dos admirables simplicidades, solo que la fractal supone una irregularidad que está presente en todas las escalas. Lo fractal suele ser rugoso, agrietado, fracturado, como las líneas de las costas, los 
copos de nieve, las nubes, el oleaje o las arboledas (2015: 334-35).

Y en el poema "Bitácora" (de El pozo), es decir la caja donde se guarda la brújula, la cual indica la dirección de la propia poesía, lo planteará de este modo:

\section{Virtual}

la presencia, el amor y su pareja

mientras trazas la exacta pulcritud

de la distancia,

Zenón, Zenón de Elea,

tu abstracta división al fin materia

en las heladas aguas del cálculo egoísta (2015: 200-01).

Zenón de Elea señala la imposibilidad de llegar, de la plenitud del ser en el pensamiento infinitesimal ("el tiempo de Zenón / que siendo nada se dilata", dirá en "Ahora", de Canto rodado, 2015: 128)3. Siempre una distancia ontológica, por mínima que sea, como en el magistral "Los siete mensajeros" de Dino Buzzati. Pero por eso mismo y por el hecho de que somos deseo y tiempo, la vida coincide con el ser solo un instante en plenitud - la aspiración de Spinoza - y, necesariamente, desemboca en lo discontinuo y en el deseo nuevamente de ser. Aquí se expresa, aunque de manera alusiva, esa final e irreductible distancia. Ya se sabe que Zenón de Elea es conocido por sus paradojas o aporías, especialmente aquellas que niegan la existencia del movimiento o la pluralidad del ser, intentando probar que debe ser homogéneo, único y, en consecuencia, que el espacio no está formado por elementos discontinuos, sino que el cosmos o universo entero es una única unidad. Sus aporías contra la pluralidad como estructura de lo real, contra la validez del espacio, contra la realidad del movimiento, o contra la realidad del transcurrir del tiempo, podrían llevarnos muy lejos, utilizando la demostración ad absurdum (absurda como cualquier reducción, al fin y al cabo). No obstante, nuestro autor define la poesía:

${ }^{3}$ No en vano la cita que abre A un mar futuro, de Saint-John Perse, es la siguiente: "Tu te révéleras, chiffre perdu!..." (2015: 238). 
La poesía es una regularidad capaz de expresar las dimensiones irregulares de la vida, el contorno cambiante de una nube, el fluir de un río, la palpitación de una pasión abriéndose paso entre la multitud anónima a la búsqueda de un rostro único (2015: 335).

La diferencia entre el fractal que se relaciona con el ser único, y la geometría euclidiana, dispersa, bien podría ser el poema, en el rescate o reducción del texto como espacio de descubrimiento, pero también de encuentro, resultado de lo que Althusser denominó materialismo aleatorio. Así es la naturaleza, imprevisible en su perfección/imperfección, pureza/ impureza, etc. José Carlos Cataño la definió como "poesía sin maleza" (1997: 11). De lo que resulta una suerte de texto esculpido como piedra, talla o miniatura cincelada de manera exclusiva, "edificio" de palabras que desde la superficie de la tierra — preguntándose constantemente por la tierra - no deja de mirar a las estrellas, como una indagación incesante del sentido del hombre en el mundo, desde la física, la geometría, la astronomía, etc. Como en el poema homónimo del libro, "Gravitación":

\section{Hay un deseo que toma los trenes \\ y cruza los idiomas \\ y los cuerpos nocturnos \\ de las constelaciones (2015: 35).}

Hay cierto orientalismo (ver García Martín, 1990: 40) humanista que nos evoca lejanías. Aunque se contemplen los astros, los personajes que aquí dejan sus huellas - en el imaginario y en la página - palpitan en "este tú y yo tendidos en la noche / mientras se alejan las constelaciones" (en "Para no olvidar", de Hora rasante, 2015: 173). "Ruedan / por estas horas baldías / constelaciones." (en "Tres", de El pozo, 2015: 218). Nosotros, en consecuencia, asombrados ante ese edificio, ciudad urbanizada y trazada, y murallas y caminos, observamos lo que queda en nuestro proceso arqueológico que deja al descubierto lo más reciente, y que debe ser meticulosamente restaurado capa a capa. En medio del desierto de la vida cotidiana, la poesía de Juan Malpartida es piedra que sobrevive... como las metáforas vivas, que han fosilizado el lenguaje, para que permanezca. Pulida y gastada, Canto rodado, recuerda de manera lejana al poema de León Felipe: 
por una parte, el desgaste vital a que el paso del tiempo nos condena, ese anónimo redondeamiento que tan bien simbolizan las piedras de los rios, sometidas, como el hombre, al constante fluir del entorno; y por otra, la palabra, el canto a través del cual se depuran nuestras percepciones y nuestros recuerdos, y en el que encarna nuestra consciencia (Moga, 1997: 24).

Piedra como constructo no solo lingüístico - lo apuntábamos antes - sino como símbolo en el que erigir una concepción del mundo y la vida en relación con las ideas. Si buscáramos detenidamente, la piedra es tal vez el elemento que más aparece en la poesía de Juan Malpartida. Y esas huellas, por tanto, están esculpidas - han sobrevivido, son vestigios-en la piedra. Se erige incluso en "Método", en El pozo: "Caminé por un reflejo, / resuelto en piedra, ya polvo" (2015: 235). Desde "La piedra escrita" (de Espiral, 2015: 22), "el deseo de ser piedra" en "Una meditación" (de Gravitación, 2015: 34), el poema en prosa "Piedra contra piedra el vacío" (de Bajo un mismo sol, 2015: 73), hasta Canto rodado, que comprehende a la piedra desde el propio título. O también desde el recordatorio "no olvides que es ingrávida la piedra / sobre las manos de tu pensamiento" (en "Para no olvidar, de Hora rasante, 2015: 172), hasta "la piedra que habla sola" (de "Piedra", de nuevo de El pozo, 2015: 198). Así podríamos citar muchos más momentos, que son más bien pasajes discursivos, jalonando el conjunto de esta obra. En contraposición, el otro motivo quizá más repetido, el mar ("eje metafórico bidireccional del pozo" que organiza "el dinamismo de la indagación poética", Díaz de Castro 2002: 27), lo que se llama también símbolo bisémico, no se concibe sino como punto final de la tierra, espacio desconocido a explorar, aventura vital en el misterio del más allá, en suma: otredad que nos indaga a saber quiénes somos nosotros mismos.

\section{DEL OTRO LADO}

Este montón de hierbas

dando vueltas por el patio, es un pensamiento.

Sin raices, el aire las mantiene. 
Las sombras crecen,

el patio se oculta.

Las hierbas son

un charco de tinta.

Cierro los ojos:

en el centro de la hora,

el mundo ingrave.

El pensamiento es hierba,

estoy del otro lado de la mente (de Hora rasante, 2015: 155).

Otredad que se expresa en muchos momentos de la obra poética de Juan Malpartida, como en el "Díptico" "Siete de la tarde y el mar inmenso: / lo que en mi oído rima es // de otro mar, espuma, piedra o nube [...]" (2015: 36), en el poema en prosa "El sueño de Sísifo": "Aquí, bajo el calor de tus labios y de tu sueño, se oye el rumor de otra ciudad bajo el arco impalpable del deseo" (2015: 43), ambos de Gravitación 4 ; o en "El pozo", del libro homónimo: "A veces, con temor y sigilo, me asomaba / y veía al otro [...]" (2015: 182). Es: "yo mismo hablando a solas con el otro, / con el vivo que soy" (de "Testigo", 2015: 191). Un yo que a través de la incisión en el misterio de la escritura se ha convertido en otro: "cercanía / que abre la puerta a lo desconocido, / y, también, el rostro vuelto muro impenetrable / donde golpeo con mi rostro, ya puro piedra." (de "Tejido de aire", 2015: 193). Rostro-piedra-muralla. "De pronto abro los ojos y mi cuarto / es la traducción de otro cuarto donde duermo [...] Los muros se resquebrajan y el mar / cruza mi cuarto" (de "Círculo", 2015: 195-96). De la intimidad del rostro y la habitación, a la representación de la piedra y la muralla, la ciudad, en sólido correlato objetivo. Por eso la "ciudad" que aparece en primera instancia, y que las excavaciones arqueológicas de nuestro análisis dejan al descubierto (en su hasta ahora última publicación), se titula $A$ un mar futuro. ¿Un personal e intransferible - transferible solo a través de la poesía - descubrimiento de la Atlántida? Se trata de todo un hallazgo, que se nos revela al leer la obra reunida de Juan Malpartida. Algo se cierra, aunque no sepamos la extensión del círculo, porque algo choca y se desgasta: "el mar, el mar de siempre, / arrasa sin cesar todas las huellas."

${ }^{4} \mathrm{La}$ piedra se tematiza a través del mito, la cual vuelve a aparecer como "antigua certidumbre de la roca" en "He visto, Sísifo" (en "Cuatro poemas", de A un mar futuro, 2015: 300). 
(en "Hélice", 2015: 312). Desde el epílogo de Huellas se configura no solo su concepción de la poesía, sino ese itinerario vital que desemboca en el mar, en el futuro de la palabra, a través de su experiencia poética:

Comencé a leer tardíamente, a los quince años: prosa reflexiva y poesía, apenas novelas. Hasta entonces, mi mundo literario, que sin duda había existido de manera difusa, se había apoyado en el habla, que fue donde se inició y donde se sostuvo históricamente: aliado al soporte de la memoria, hasta la fijación, tímida al principio, de la escritura (2015: 317).

Toda escritura posee un esbozo biográfico, sus obsesiones y sus coordenadas, con la distancia que otorga la madurez, pero ahora el recorrido - a la hora de analizarla, pues vamos hacia el origen, hacia el punto de partida - es inverso. No en vano define la poesía:

La poesía tiene que ver con los signos y con los sueños, con lo que hacemos todos los días o no hacemos nunca, con la resistencia de la realidad, con la vida y con la muerte. [...] Un poema se escribe de muchas formas, y no solo ahora, herederos de los espacios del romanticismo, del modernismo y de las vanguardias (2015: 326-27).

\section{LA OTREDAD DIALÓGICA DE $A$ UN MAR FUTURO}

Bajo advocación cernudiana, $A$ un mar futuro recuerda a "A un poeta futuro" del sevillano, incluido en Como quien espera el alba (1947), uno de los poemas más influyentes del siglo XX y lo que va del XXI. No será el único homenaje al poeta muerto en Ciudad de México en 1963: en "Recomienzo" (2015: 291-92) se realizará otro intertexto con "Noche del hombre y su demonio" (también de Como quien espera el alba) cuando el poeta escribe, al inicio del poema: "Tras la noche del llano y su demonio". A un mar futuro es un poemario lleno de resonancias y tensiones. Dividido en tres secciones nítidamente diferenciadas, la primera, titulada como el libro, "A un mar futuro", plantea ciertos acordes donde, a través de esa prosa poética que nos viene acompañando, se vehicula la emoción del recuerdo que aflora, como un pecio - de nuevo la arqueología, esta vez submarina, poesía espoleada por el recuerdo del padre contando historias - del fondo 
oceánico. Estas prosas de gran calado y lenguaje punzante, herido, lleno de referencias y analogías, densidad y enlazadas en un relato de la conciencia y la memoria que va urdiendo un magma verbal siempre vivo e hirviente, con pertinentes idas y vueltas hacia el presente, emergen desde los años de la infancia, evocada con temor y temblor. El futuro de entonces, cuando el autor - convengamos en que coincide con el sujeto poético- era pequeño, es el presente de hoy: "Mi ahora de entonces es el de ahora" (2015: 244). La intensidad de estos dieciséis poemas en prosa (solo uno va en verso, el titulado "13 (Playa)", 2015: 260-61)5, crea en esta lectura integral, puntos de conexión que se enlazan rítmica y temáticamente al conjunto. Amalgama estas prosas y las compacta la mezcla de elementos heteróclitos, de estirpe teórica - metapoesía, autorreferencialidad (ver Martínez Morán 2015: 32) - y fragmentos líricos. El recuerdo funciona como un sustrato que hay que ir limpiando o escarbando, descubriendo desde la lectura. "El palimpsesto es para para él [Juan Malpartida] la posibilidad de higiene poética" (Medina Portillo, 1996: 39). La circularidad engloba la narración, como en "4" (2015: 245-46), pero también a la memoria, estableciendo una correa de transmisión entre la infancia, los relatos del padre y sus deseos de ser poeta de entonces, de ser "mar", junto con la mirada a veces nostálgica y otras arrasada, del que contempla sincréticamente todo. Ya en El pozo se podía vislumbrar este metódico "Tránsito" (2015: 187) hacia el mar, "del pasado al presente", ya que "del futuro a la nada / hay un mar de palabras" (2015: 187) ${ }^{6}$. El relato oral de entonces es el relato escrito de hoy, que vuelve muchas veces a un mismo lugar tratando de situarse, resituarse, en la búsqueda de la propia identidad, desde la relación dialógica que establecemos con el Otro: "Pero tú estás en otra parte, en el otro lado de este lado" ("6", 2015: 250), estableciendo una ligazón con el primer poema: "en otro siglo, en otra ciudad, en otro." (“1”, 2015: 239), junto a un nutrido panorama de imágenes sugerentes y emotivas que conforman un espacio imaginario en la conciencia, que se traducen y vuelcan en el

\footnotetext{
${ }^{5}$ Para simplificar, cuando sea necesario, aquí los citaremos por el número, refiriéndose todos a "A un mar futuro" (2015: 239-67).

${ }^{6}$ Víctor García de la Concha planteaba a propósito de Canto rodado que "No es verdad que haya siglos que gravitan sobre el instante presente. Los ojos del poeta lo ven al revés: es el instante el que, desplazado por el viento de la palabra poética, se desplaza a la deriva por la vastedad de los espacios" (1996: 8), y nos parece aplicable al conjunto de su obra.
} 
texto como un lugar real, esos restos arqueológicos que afloran ${ }^{7}$. La fuerza narrativa de los pasajes nos traslada. Y ese lugar habita un estuario, como en el inicio de "5":

Aquel camino junto al estuario y la cortina de juncos azotados por nubes de moscas, los latidos del muchacho empujando los límites al internarse -un paso más, un paso más y el mundo cede- es una realidad indecisa en las horas inciertas (2015: 247).

El complejo dialogismo de estirpe bajtiniana no simplifica nada. Antes bien, en el sujeto poliédrico contemporáneo nos encontramos "Sin semejantes" (de El pozo, 2015: 223). "Pero es el otro lado, ese otro lado de las cosas y de uno mismo, que ha obsesionado desde siempre a los escritores, el que ofrece al poeta un consuelo y una esperanza" (Moga 2015: 92). En realidad, nos tratamos a nosotros mismos como si fuéramos un actor (2015: 223), y así logramos dialogar con — monologar en — nuestra conciencia. No por casualidad en el poema siguiente, "Cordialmente suyo (Fernando Pessoa)", se desarrolla irónicamente el asunto pessoano de los heterónimos:

\author{
Soy, \\ como todos nosotros, \\ una ficción del intermezzo, \\ falso como las horas que pasan \\ y las obra que permanecen \\ en el remolino subatómico \\ de este inconcebible universo $(2015: 224)^{8}$
}

\begin{abstract}
${ }^{7}$ La dialéctica luz/sombra ha sido detectada por Álvaro Valverde: "Se aprecia que la visión y la memoria, como subrayó Valente, otro de sus maestros confesos, son claves a la hora de definir esta poesía tan oscura (en el mejor sentido, por lo que deja entrever, sugiere y calla) como luminosa (por lo que describe y expresa)" (Valverde, 2012).

${ }^{8}$ Nuestro autor argumenta: "Y el convencimiento de que la soledad / acompaña, rige las efusiones, / rima con la fatal conciencia / de ser uno, de ser dos, y ninguno." (versos finales de "Sinceridad", de A un mar futuro, 2015: 307). Orlando González Esteva sitúa estas problemáticas en la revelación de "una conciencia de los poderes y los límites del lenguaje, de la extrañeza del ser y el estar, de un más allá que no comienza en los espacios estelares ni en la muerte sino en su propio hogar, entre las cosas que le rodean, en las calles que recorre, en las palabras que utiliza a diario e incluso en sí mismo; un más allá que es un más acá y cuya interrogante sustenta sus dos vocaciones mayores: la
\end{abstract}


La segunda parte de A un mar futuro se titula "Enredadera", y presenta una serie de composiciones breves, en su mayoría haikus (en un ejercicio de orientalismo - antes señalado - llevado a su extremo), pero alternada con otras estrofas, siempre de cuño breve, que bien podría simular precisamente eso, una enredadera, el trenzado vegetal y de las ramas, que va naciendo y creciendo y de algún modo fosilizándose en el signo lingüístico, en esa palabra ansiada y perseguida... principio y fin. También los haikus han sido - fueron - ensayados a lo largo y ancho de estas Huellas, como en gran parte de la sección "Talle del aire", de Gravitación, aunque podríamos encontrar más en un rastreo exhaustivo ajeno a nuestro propósito. Solo baste citarlo. En la exactitud de la composición breve, donde no sobra nada y cada palabra adquiere rasgos infinitamente polisémicos, se atrapa el instante de manera precisa, y es un minuto de oro que va alargando su duración, brillando como en una eternidad. Los poemas a la luna, a la mirada que interpreta la realidad, o las reflexiones sobre el tiempo ido, adquieren una dimensión mucho mayor que la estrofa que las acoge, en una decantación sabia y meditada, densa y sólida. Un orientalismo que se asimila desde la otredad. Además, podríamos añadir que, como dice un proverbio japonés, "cada momento es único, solo sucede una vez."

La tercera parte de A un mar futuro se titula "Recomienzo", y en ella casi todos los poemas son en verso, excepto uno en prosa, "Vigilia" (2015: 302-03), jugando también con la primera sección aludida, y estableciendo un vínculo o guiño formal. El contrapunto estrófico y estilístico de una parte y otra, deshaciendo el nudo lúdico de la segunda, nos ofrece un variado repertorio de estructuras que hablan - utilizando el símil del título- del poeta ya maduro que utiliza los versos según le conviene, canalizando en cada cauce textual la emoción, tal y como quisiera Eliot, del que por cierto nuestro poeta es un excelente traductor. Un poema como "Vigilia" nos sorprende en sus cuatro partes, muy breves y condensadas las tres primeras en prosa, rematadas por la última, en verso. De nuevo la dialéctica verso/ prosa. No son casuales estas elecciones y nos hablan de algo más que buen oficio de Juan Malpartida, que hace de las formas estilísticas un sistema expresivo.

reflexión y la poesía” (2015: 27). 
El mar de ahora fue un soñado mar de entonces, adivinado desde siempre, como en "Paraíso", de El pozo: "Tenía quince años y el mar enfrente, / el oído sobre la piedra" (2015: 186), igual que el poeta de ahora fue un soñado poeta entonces. El mar es el filtro desde el que se ve todo, el lenguaje o logos que destila el libro, el eje textual sobre el que nos apoyamos. Porque en el ahora contemplamos el mar de ayer, pero también imaginamos quiénes éramos y quiénes queríamos ser: "No sé si tuve infancia [...] Crecer fue despojarme, hasta envolver la nada" (2015: 69-70), aseveró ya en "La casa amenazada", de Bajo un mismo sol, poema donde el poeta penetra en las complejidades y mundos de reflejos de la infancia. En la supervivencia de las ilusiones el pasado de entonces puede convertirse en futuro del ahora, nuestro presente como lectores, que habitamos el poema. Por eso de esta última sección destacamos de nuevo "Recomienzo" (2015: 291-92) en su circularidad, y quisiéramos citar también "Memorial" (2015: 293-97), la más larga de las composiciones del libro, pues entronca directamente — por los temas: la infancia, el recuerdo del padre, la promesa del mar como horizonte de futuro- con la primera parte. En este sentido no podemos olvidar un poema importante como "Vestigios" (2015: 305-06), ya que engancha con la noción expresada de arqueología. Sus dos primeras estrofas dicen así:

Hay días en que recuerdo
la vida en el paleolítico,
los duros ciclos del hielo
y los cuidadosos golpes
de la piedra, su sonido.

Días en los que al mirar el cielo azul, tan intenso, en algún lugar del cuerpo me revive la nostalgia de respirar por las branquias (2015: 305).

"Vestigios" que son la última sección del libro anterior, El pozo. Como vemos, no son vanas - ya lo advertimos - estas imbricaciones formales, este trenzado temático, que habla de una "obra en marcha" juanramoniana, como apuntara Gustavo Guerrero (2002a: 87-88), que 
leemos desde su resultado, el conjunto de estas Huellas: "Las huellas de nuestros pies: seguidas, ahoyadas, borradas [...] las huellas de dos seres erguidos caminando juntos, hace tres millones y medio de años [...] Huella de la huella, la semilla en el fondo de la retina, la almendra de la memoria en su tumba de siglos" (en " 2 ", de $A$ un mar futuro, 2015: 240-41). ¿Desembocamos en una concepción más amplia? ¿Ruinas simbólicas de ciudades mesopotámicas? Desde esos zigurats abstractos, ¿sigue el hombre preguntándose por su identidad, su origen, su destino, al contemplar las estrellas? Las referencias van más allá incluso, abarcando el atavismo, la prehistoria o el mito, y aludiendo a un pasado remoto que se construye y del que aún podemos formar parte, visible "en la cueva de una palabra inmensa" (en "El fantasma y sus apariciones", de Bajo un mismo sol, 2015: 67-68). La poesía, única respuesta como construcción de sentido. De hecho, Bajo un mismo sol constata cierta búsqueda de la inmanencia - sin alguna ingenuidad chomskiana - biológica del hombre, a pesar de las determinaciones culturales que lo modifican, en las pulsiones erotanáticas (ver "Crónica", 2015: 101-02) que, sin embargo, hacen de la sexualidad algo muy distinto al deseo. Y en esa contradicción paradójica se halla también esta poesía, que no obstante posee esos referentes antropológicos — bien apuntalados — de una arqueología foucaultiana de las ciencias humanas.

\section{DIARIO DE BITÁCORA \\ (Mar de fondo)}

Lo irreal es demasiado táctil

y ha cercado a las cosas de un temblor

de platino y quijada antigua. Su sombra,

sobre el perfil del cuarto,

tiene más cuerpo

que estas manos empeñadas

en acariciar un rostro

ya desvanecido en el tacto (de Bajo un mismo sol, 2015: 79).

En la tensión del atavismo — “quijada antigua" — y la abstracción tecnológica se combina el sensismo, decisivo para comprender esta poesía, como en "Otra vuelta de tiempo" (2015: 94-95), donde se plantean de 
manera circular los temas del autor: de vita brevis, tempus irreparabile fugit, el ser y el tiempo, el ser y la nada... Una "tensión narrativa" (Abril 2013: 443-45; luego ampliado en 2015: 43-47) que, como resumen del resumen, podríamos exponer aquí con este breve texto a modo de conclusión, donde la piedra - representada a través de la lápida — viene desde la prehistoria hasta hoy, trayéndonos la fugacidad de la palabra en la memoria de un pasado que vuelve (ver Lama, 2013: 117), que pretende perdurar:

\section{EPITAFIO}

Vivió en la era interglaciar:

un poco de calor entre dos bloques,

y estas vanas palabras sin destino (de El pozo, 2015: 215).

Más que una declaración de intenciones, se trata de una cuestión de principios. No solo valores, los cuales son innegociables, sino orígenes, búsqueda e indagación incesante, "Carta futura" (en "Cuatro poemas", de A un mar futuro, 2015: 301) desde la memoria. Un legado que sobrevive al tiempo. Y eso es impagable. Porque aquí está. Sobrevive.

\section{A MODO DE BREVE CONCLUSIÓN}

A partir de los comentarios sobre el valor de la metáfora, las huellas, el lenguaje y la otredad, la poesía de Juan Malpartida ha construido una semiosfera al modo lotmaniana de significación que trasciende el texto para crear sentido. Huellas que se borran, como quería Blanchot, pero que crean un sentido del itinerario descrito, en ese ir y venir del lenguaje... El resultado para el lector va más allá del placer estético, para instalarse en lo que Paul Ricoeur llamaba metáforas de creación, que innovan, dotando al lenguaje de su tiempo mayor profundidad y complejidad. Esa es la grandeza de esta poesía, su rica y abierta tradición.

\section{REFERENCIAS BIBLIOGRÁFICAS}


ABRIL, J. C. (2013). “Tensión narrativa”. Turia. Revista cultural 107, 443-45.

(2015). "Huellas (Poesía 1990-2012)". La Manzana Poética. Revista de Literatura, creación, estudios literarios y crítica 39, 43-47.

BLANCHOT, M. (1994). El paso (no) más allá, trad. de Cristina de Peretti. Barcelona: Paidós.

CATAÑO, J. C. (1997). "La poesía sin maleza de Malpartida". El País (Babelia), 8 de febrero, 11.

COBO, E. (1990). "La vida como dolor". El Independiente, 29 de marzo, 7.

COSTA, H. (1991). "Malpartida: el tacto y la distancia". En Bajo un mismo sol, J. Malpartida, 5-7. Ciudad de México: El Tucán de Virginia.

DÍAZ DE CASTRO, F. (2002). "El pozo”. El Mundo (El Cultural), 26 de diciembre, 27.

DOCE, J. (1997). “El canto redondo de Juan Malpartida”. Ínsula: revista de letras y ciencias humanas 605, 19-21.

(2002). "Presencias pensadas". ABC (Blanco y Negro Cultural), 16 de noviembre, 14.

(2007). "Presencias pensadas". En A favor del tiempo (Antología), J. Malpartida, 11-20. Madrid: FCE.

FERRER SOLÁ, J. (1990). "Otra vuelta de tuerca". Anthropos. Revista de documentación científica de la cultura 109, xx.

GARCÍA DE LA CONCHA, V. (1996). "Canto rodado". ABC literario, 5 de julio, 8. También, posteriormente, en La Manzana Poética. Revista de Literatura, creación, estudios literarios y crítica 39 (2015), 9-10.

(1997). "Hora rasante". ABC literario, 17 de octubre, 9.

GARCÍA MARTÍN, J. L. (1990). "Un premio inmerecido". La Nueva España, 26 de enero, 40.

GONZÁLEZ ESTEVA, O. (2015). "El indecible don de sabernos tiempo". La Manzana Poética. Revista de Literatura, creación, estudios literarios y crítica 39, 27-29.

GUERRERO, G. (2002a). "Obra en marcha". Letras Libres 47, 87-88 (también en https://www.letraslibres.com/sites/default/files/files6/ files/pdfs_articulos/pdf_art_7912_6782.pdf [31/12/2018]). (2002b). "En esta orilla, en este tiempo". Lateral: revista de cultura $95,20$. 
LAMA, J. G. (2013). “A un mar futuro”. Paraíso. Revista de poesía 9, 11517 (también en https://www.dipujaen.es/export/descargas/cultura/ revista-paraiso/paraiso_9.pdf [31/12/2018]).

MALPARTIDA, J. (1990). Espiral, prólogo de M. Ulacia y contracubierta de Octavio Paz. Barcelona: Anthropos.

(1991). Bajo un mismo sol, introducción de Horacio Costa. Ciudad de México: El Tucán de Virginia.

(1996). Canto rodado. Valencia: Pre-Textos.

(1997). Hora rasante. Madrid: La Palma.

(2002). El pozo. Valencia: Pre-Textos.

(2007). A favor del tiempo (Antología), prólogo de J. Doce. Madrid:

FCE.

(2011). Al vuelo de la página. Diario 1990-2000. Madrid: Fórcola.

(2012). A un mar futuro. Madrid: Visor (IX Premio de Poesía Fray

Luis de León).

(2015). Huellas (Poesía 1990-2012), epílogo del autor. Barcelona: La Garúa.

MARTÍNEZ MORÁN, F. J. (2015). "Huellas (Poesía 1990-2015)". Paraíso. Revista de poesía 11, 31-33 (también en https:// www.dipujaen.es/export/files/dipujaen/revista-paraiso/revistaparaiso-11.pdf [31/12/2018]).

MARTÍNEZ RUIZ, F. (1990). "Espiral”. ABC literario, 3 de febrero, iv.

MEDINA PORTILLO, D. (1996). "Canto rodado". Vuelta 236, 39.

MILÁN, E. (1990). "Coser y cantar: saldos favorables". Vuelta 160, 29-30.

MOGA, E. (1997). "Canto rodado". Lateral: revista de cultura 25, 24.

(2015). "El tiempo y sus pisadas". Quimera 380-381, 92.

MORÁBITO, F. (1998). "Hora rasante”. Vuelta 254, 47-49.

PAZ, O. (1990). "Contracubierta". En Espiral, J. Malpartida, s. p. Barcelona: Anthropos.

(2011). "Hora rasante”. En Al vuelo de la página. Diario 1990-2000, J. Malpartida, 258-259. Madrid: Fórcola.

PRIETO DE PAULA, Á. L. (2002). "El brocal del conocimiento". El País (Babelia), 9 de noviembre, 18.

RÍOS RUIZ, M. (1990). "Juan Malpartida, poeta andaluz". Diario de Jerez, 11 de marzo, 14.

SÁNCHEZ ROBAYNA,A. (2015). "A un mar futuro: tiempo, pensamiento, deseo”. La Manzana Poética. Revista de Literatura, creación, 
estudios literarios y crítica 39, 41-42.

ULACIA, M. (1990). "Palabras liminares". En Espiral, J. Malpartida, 9-16. Barcelona: Anthropos.

VALVERDE, Á. (2012). "El mar, la mar". Solvitur ambulando, 11 de octubre. Disponible en http://mayora.blogspot.com/2012/10/elmar-la-mar.html [31/12/2018].

Recibido el 11 de enero de 2019.

Aceptado el 14 de junio de 2019. 